Supplement of Hydrol. Earth Syst. Sci., 22, 1051-1064, 2018

https://doi.org/10.5194/hess-22-1051-2018-supplement

(C) Author(s) 2018. This work is distributed under

the Creative Commons Attribution 4.0 License.

(c) (1)

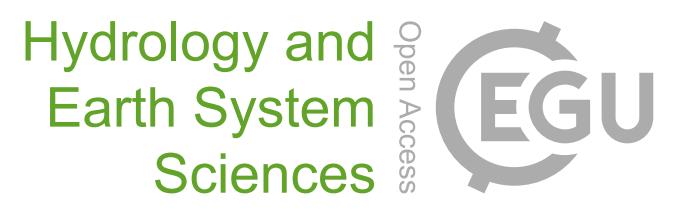

Supplement of

\title{
Human influences on streamflow drought characteristics in England and Wales
}

Erik Tijdeman et al.

Correspondence to: Erik Tijdeman (erik.tijdeman@hydrology.uni-freiburg.de)

The copyright of individual parts of the supplement might differ from the CC BY 4.0 License. 
This supplementary material presents some examples of streamflow records with deviating drought characteristics and a brief description of the catchment characteristics. More information can be found on the website of the National River Flow Archive: http://nrfa.ceh.ac.uk/. All analyses are based on streamflow records between 1974 and 2013. However, for some examples in this suplementary material, we zoom in to a particular period of record where the impact of the human influence was most clearly visible.

\section{S1 - Mimram at Panshanger Park (38003)}

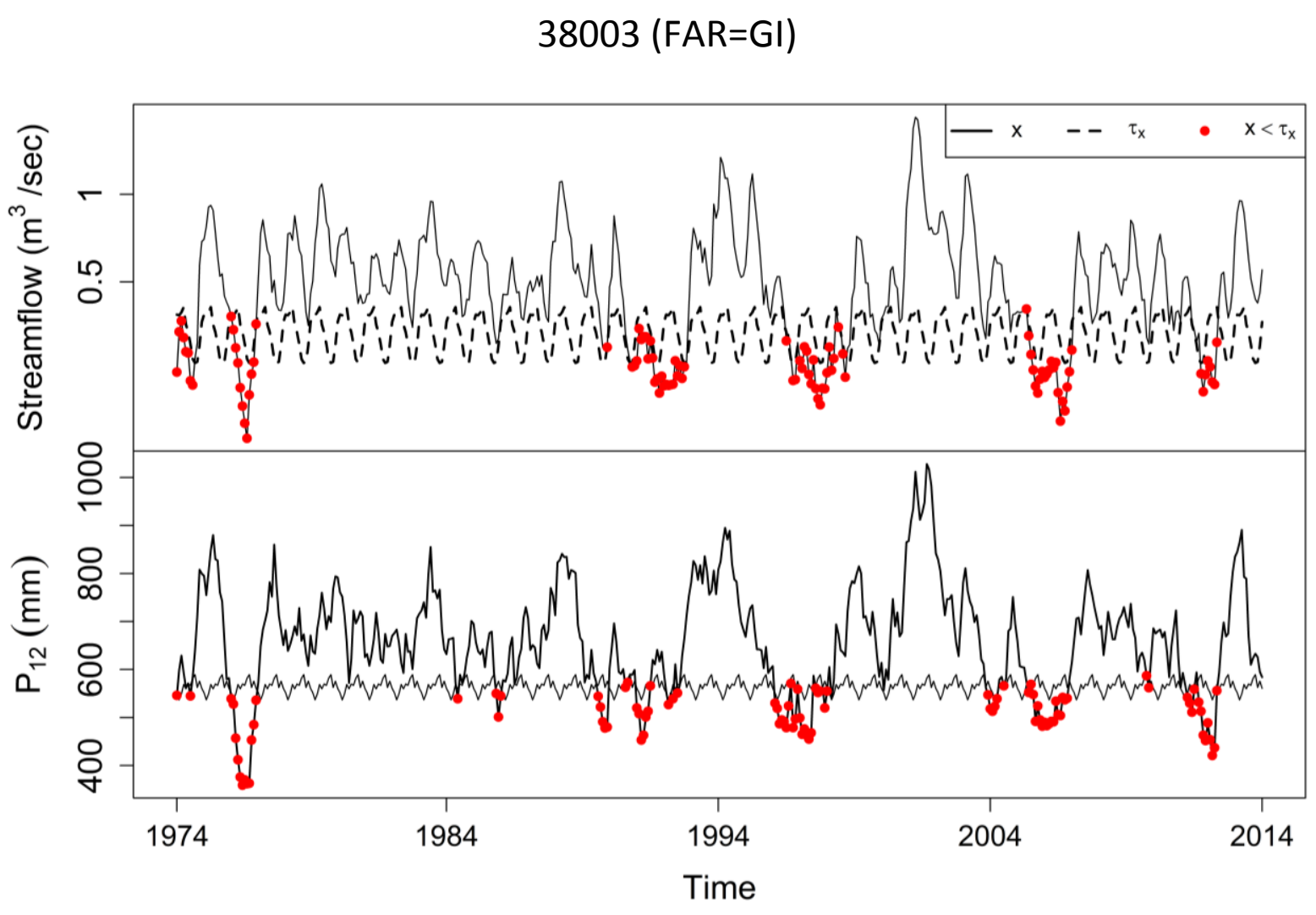

Figure S1. Monthly streamflow (upper) and precipitation accumulated over a 12 month period ( $\mathrm{P}_{12}$, lower) for the Mimram at Panshanger Park between 1974 and 2013.

- Catchment description: A predominantly permeable chalk catchment. Mainly rural but substantial urban growth in the lower valley (BFIHOST $=0.72$ ).

- Flow record/regime description: Net export of water. Considerable groundwater abstraction and abstraction for industry \& agriculture occurs in the headwaters. High Base Flow component but peak flows increasing due to urbanisation (FAR=GI).

- Time series description: Generally persistent streamflow droughts; different droughts in $\mathrm{P}_{12}$ can pool together into one streamflow drought (e.g., 2004-2006).

- Interpretation of human influences: Prolonged drought duration possibly related to both groundwater abstractions and properties of the underlying chalk aquifer. Further research needed to attribute overall impact of groundwater abstraction on streamflow drought duration. 

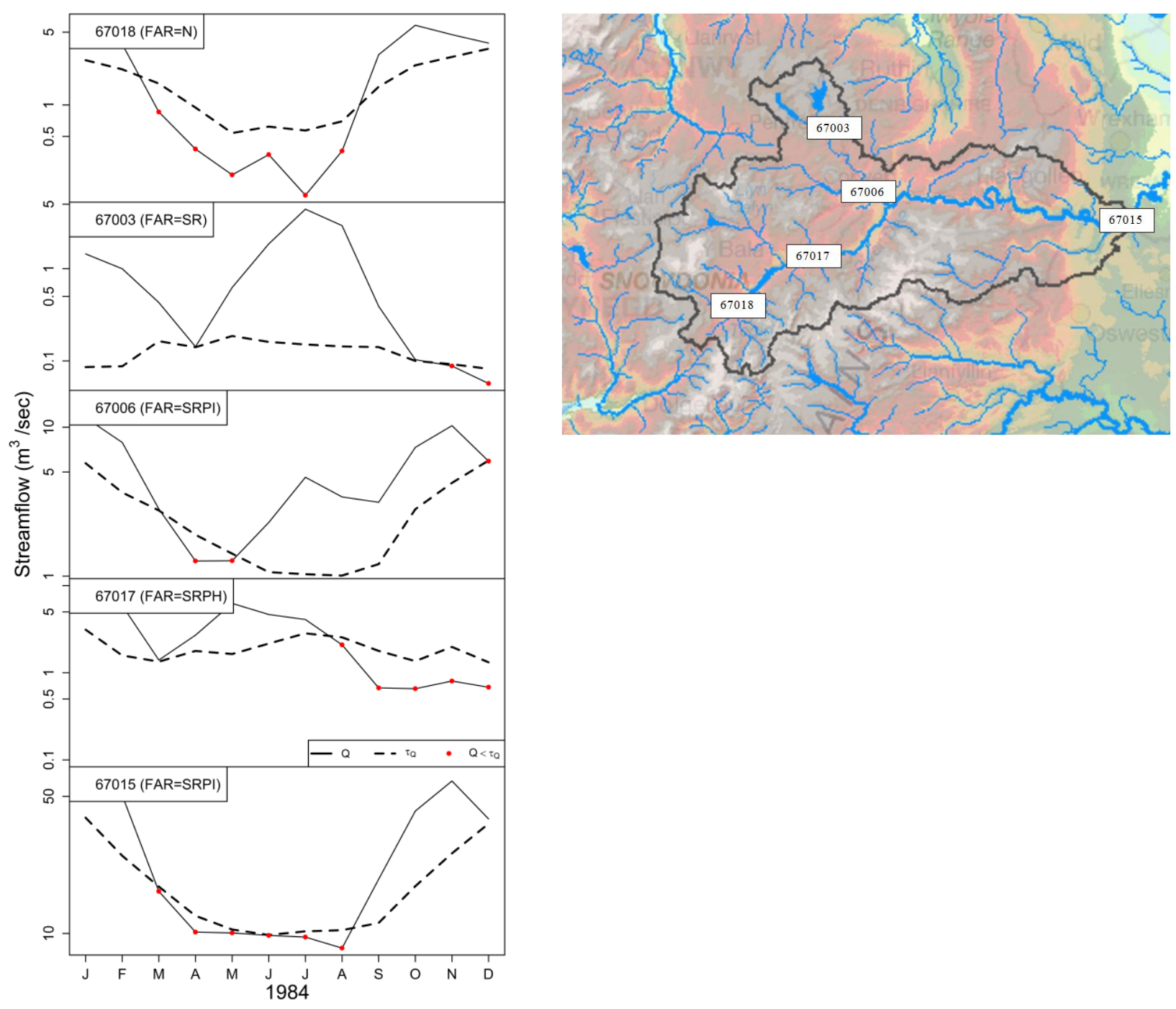

Figure S2. Monthly streamflow for different gauging stations within the Welsh Dee catchment; zoomed in to one particular year of the period of record(1984, left) and locations of gauging stations within the basin (right).

- Catchment description (67015): Predominantly impermeable catchment. Mostly grassland with some forest and upland heath

- Flow record/regime description: 67018 is a catchment with Near-natural flow upstream $(F A R=N) .67003,67006,67017$ are stations downstream of reservoirs that release water to compensate for low flows in the main branch (67015).

- Time series description: Persistent streamflow drought visible for the upstream catchment with near-natural flow (67018) and for the downstream gauging station (67015). No or minor drought visible during spring and summer of 1984 for 67003 and 67006 and only towards the end of summer for 67017. 67003 and 6017 show drought towards the end of record when the drought in the main branch is over.

- Interpretation of human influences: Impact of compensation flow clearly visible. The mismatch between precipitation and streamflow confirmed by a mismatch in streamflow between nearby stations with near-natural flow (67018 vs. 67003, 67006, 67017). Time 
series reflect spatial variability of streamflow conditions within a catchment during drought caused by human influences.

\section{S3 - Candover Stream at Borough Bridge (42009)}

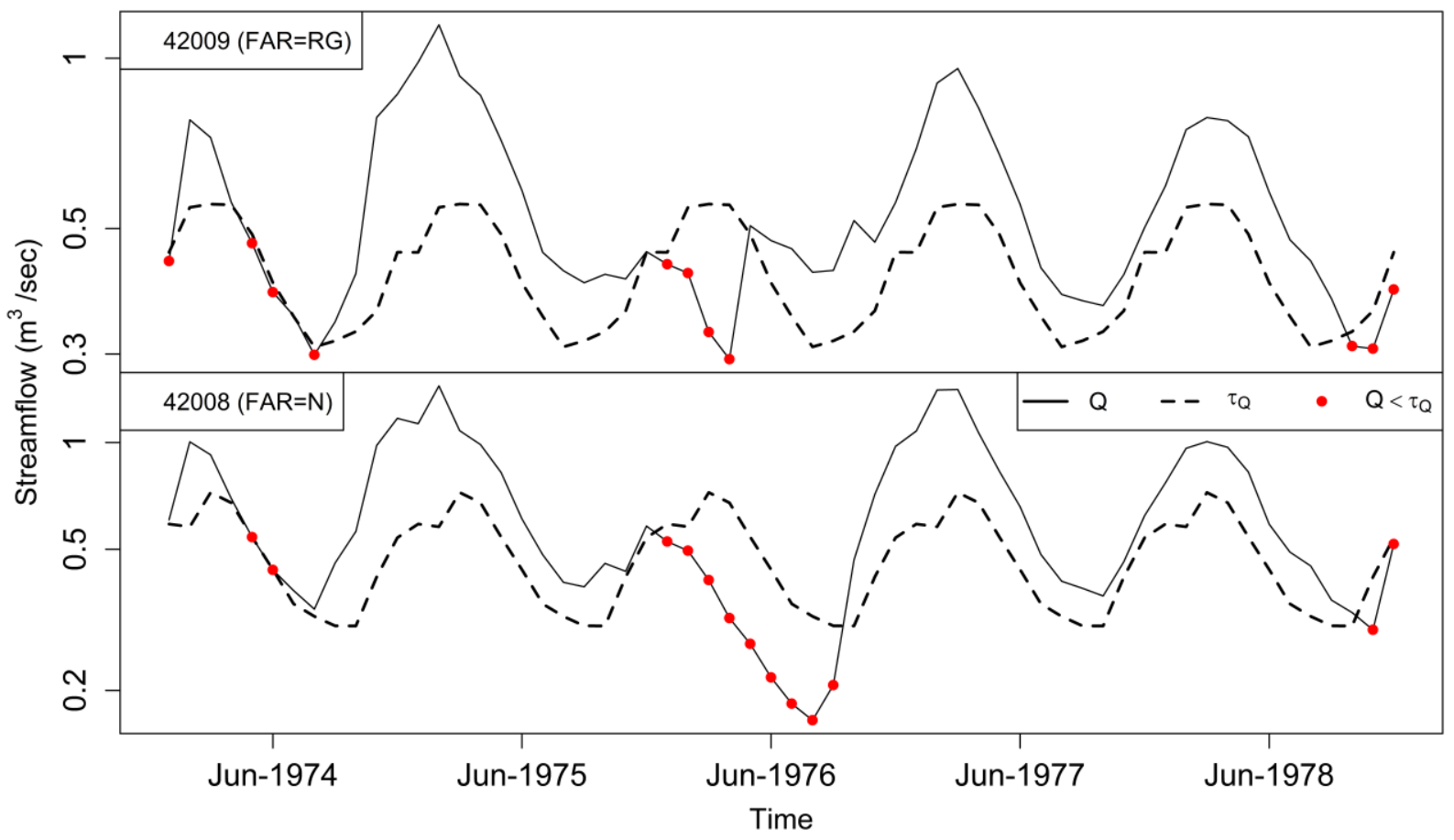

Figure S3. Monthly streamflow for the Candover Stream at Borough Bridge (upper) and the neighboring Cheriton Stream at Sewards Bridge (lower) between 1974-1978.

- Catchment description (42009): Chalk catchment with predominantly rural land use (BFIHOST $=0.95$ ).

- Flow record/regime description (42009): Runoff reduced by surface and groundwater abstractions. The impact of groundwater augmentation scheme is important in notable droughts, e.g., 1976, 1989, 2005, 2011 (FAR = GR).

- Time series description: 1976 streamflow drought gets disrupted at the end of spring whereas this drought lasted for the whole summer for neighboring catchment 42008 ( $F A R=N$, BFIHOST=0.94).

- Interpretation of human influences: Flow augmentation with groundwater likely terminated the 1976 streamflow drought. 


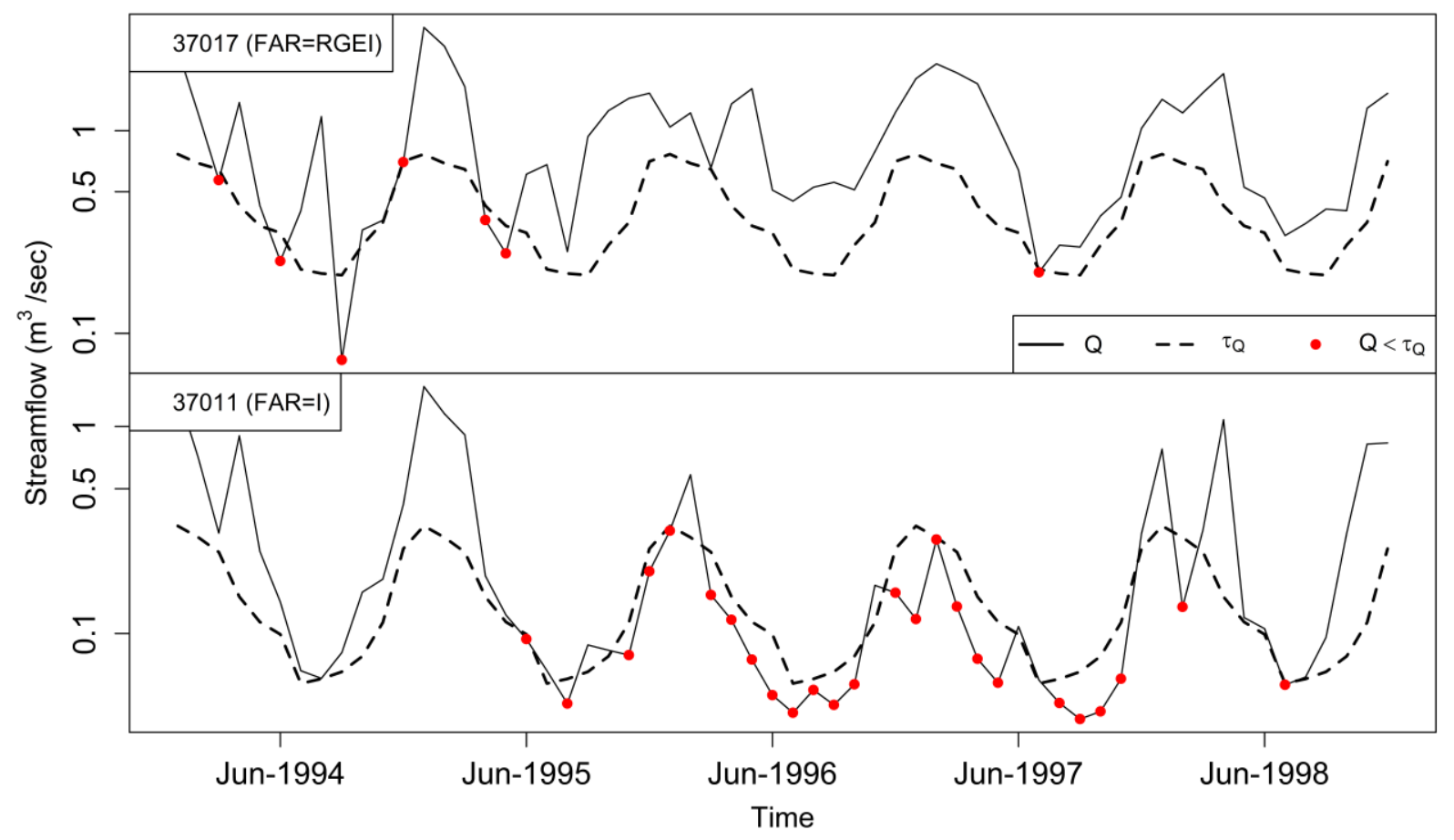

Figure S4. Monthly streamflow for the Blackwater at Stisted (upper) and the neighboring Chelmer at Churchend (lower) between 1994-1998.

- Catchment description (37017): Chalk catchment. Mainly rural (arable predominates) but with urban area in lower valley (BFIHOST $=0.49$ )

- Flow record/regime description (37017): Flows can be artificially increased by Ely Ouse transfer scheme (FAR = RGEI).

- Time series description. No drought during 1995-1997 whereas neighboring station (37011, $F A R=I, B F I H O S T=0.45$ ) showed a lot of drought months during that period.

- Interpretation of human influences: Absence of drought for 37017 likely related to Ely Ouse water transfer scheme. 


\section{$28001($ FAR=SRP)}

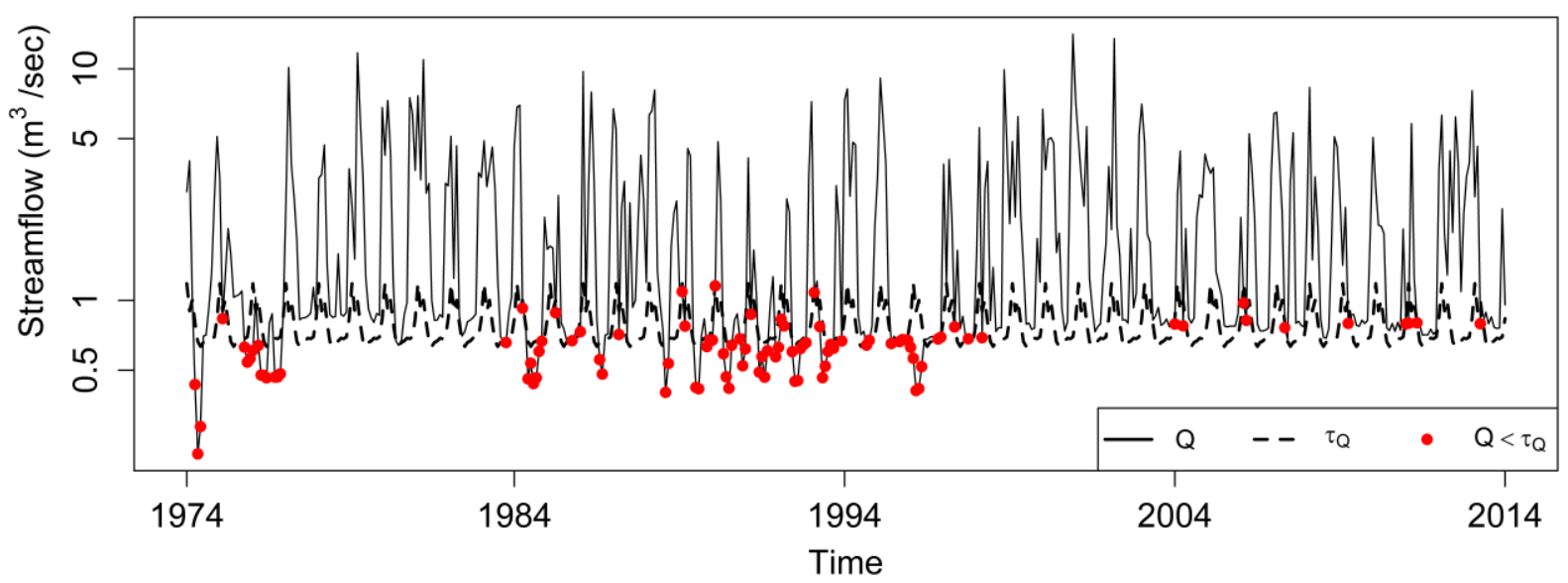

Figure S5. Monthly streamflow for the Derwent at Yorkshire bridge between 1974 and 2013.

- Catchment description: Steep moorland catchment, with extensive hilltop peat (BFIHOST=0.37)

- Flow record/regime description: Flow influenced by reservoir upstream of the catchment $(F A R=S R P)$.

- Time series description: Majority of drought months in the beginning of record, only few drought months after 2000

- Interpretation of human influences. Change in reservoir management likely decreased the amount of drought months towards the end of record. 
$47008(F A R=S H)$

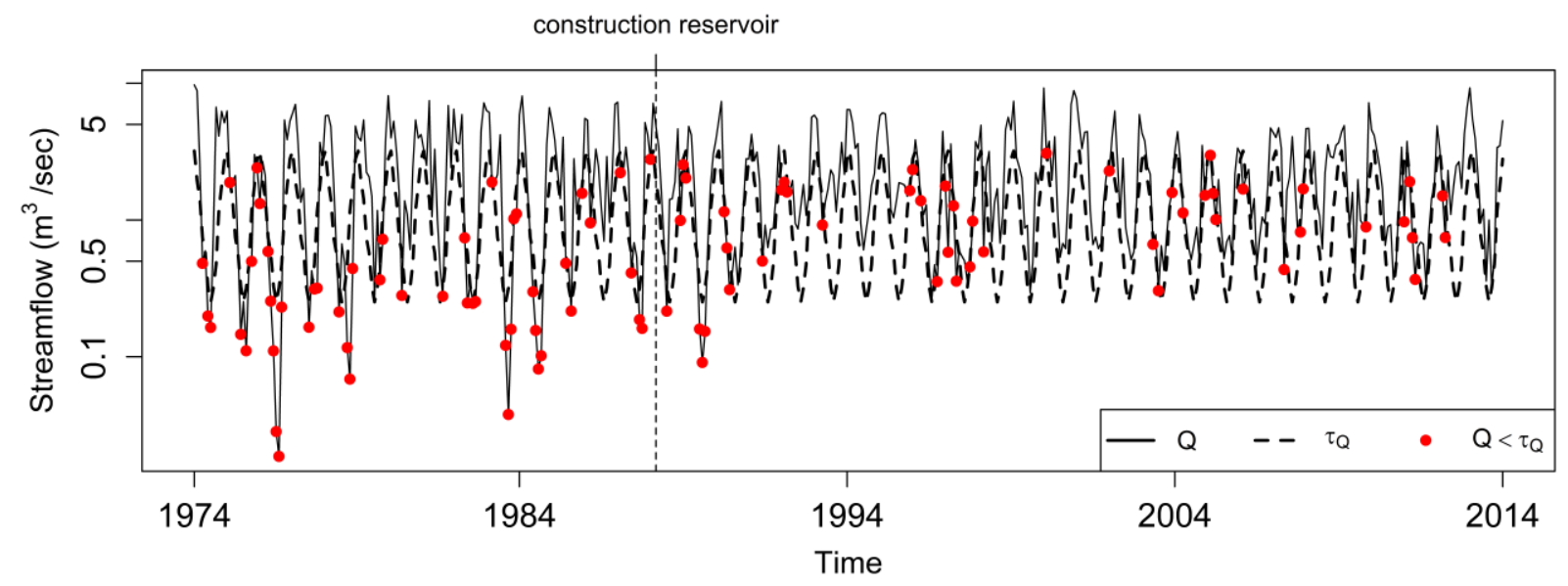

Figure S6. Monthly streamflow for the Thrushel at Tinhay between 1974 and 2013.

- Catchment description: Catchment drains shales and sandstones of Carboniferous Culm Measures. Land use is rural (BFIHOST=0.42).

- Flow record/regime description: Low flows significantly affected after 1988 by a reservoir (storage and pumped and water transfers).

- Time series description: The majority of drought months occurred in the first 15 years of record. Lesser drought months after the construction of the reservoir (FAR=SH).

- Interpretation of human influences: The construction of the reservoir impacted flow downstream, likely resulting in fewer drought months towards the end of record. 
$67003(F A R=S R)$

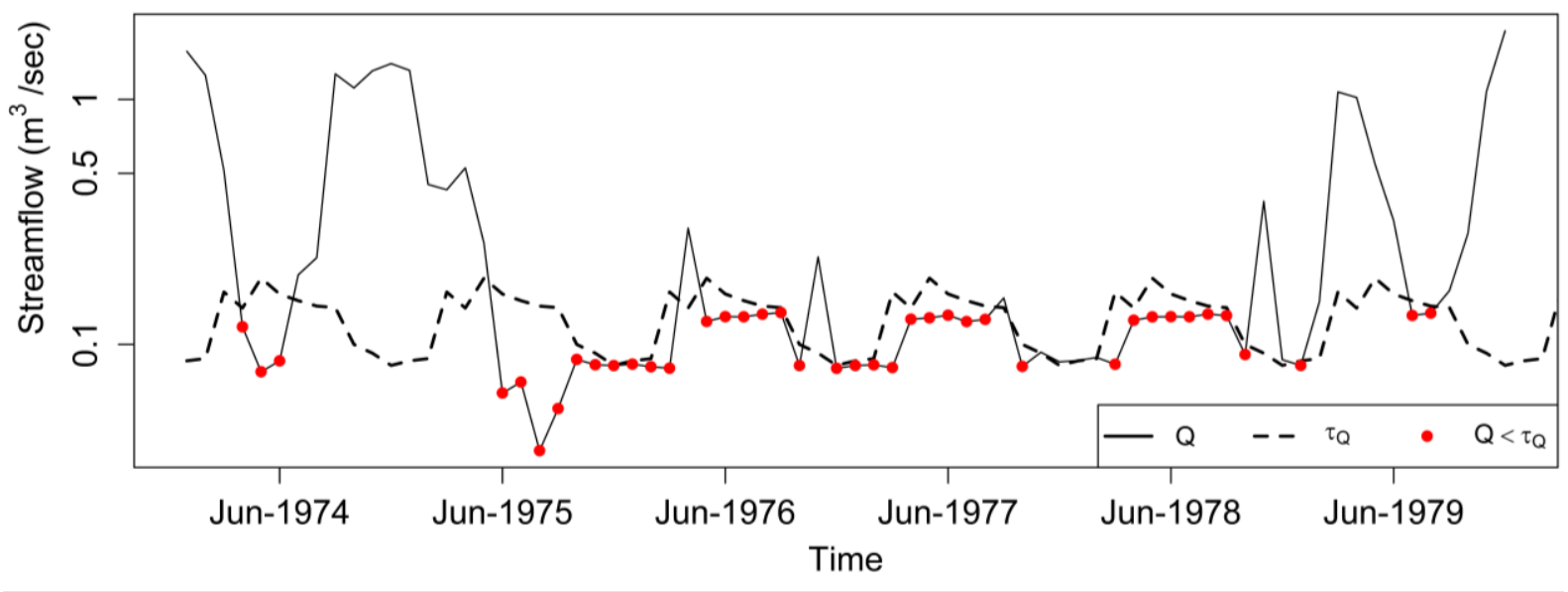

Figure S7. Monthly streamflow for Llyn Brenig outflow zoomed in to the period between 1974 and 1979.

- Catchment description: Open moorland catchment (BFIHOST=0.32).

- Flow record/regime description: Flow influenced by reservoir downstream. Impoundment started in 1975 (FAR=SH).

- Time series description: The period between 1975 and 1978 contains a large proportion of drought months.

- Interpretation of human influences: Multiyear impoundment at the start of record resulted in the occurrence of a large number of drought months downstream of the reservoir in the beginning of record (and consequently lesser towards the end of record, not shown). 
$33024(\mathrm{FAR}=\mathrm{GEI})$

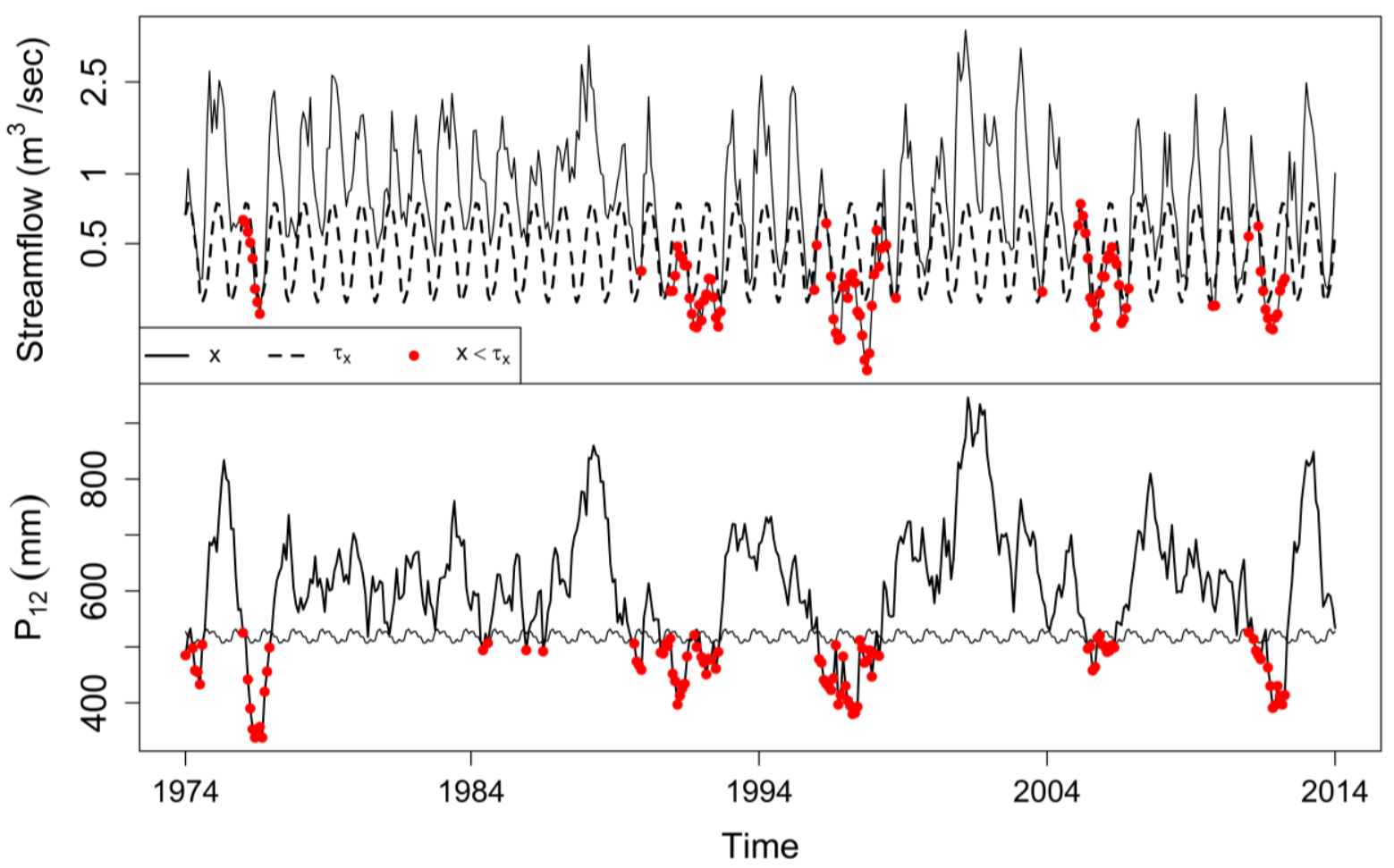

Figure S8. Monthly streamflow (upper) and precipitation accumulated over a 12-month time period $\left(P_{12}\right.$, lower) for the Cam at Dernford between 1974 and 2013.

- Catchment description: Predominantly pervious Chalk catchment with arable land use (BFIHOST=0.65).

- Flow record/regime description: Five groundwater abstractions for public water supply. Also abstractions for industry and agriculture. Flow regime is affected by industrial effluent returns derived from groundwater pumped within the catchment (FAR=GEI).

- Time series description: Droughts between 1974 and 1976 in $\mathrm{P}_{12}$ not as visible in streamflow whereas 2004-2006 drought for streamflow is not as visible in $\mathrm{P}_{12}$.

- Interpretation of human influences: Increase in streamflow drought months towards the end of record possibly related to groundwater abstractions, but it requires additional research to attribute whether this increase is really related to the groundwater abstraction or to properties of the underlying chalk aquifer. 


\section{$40012(\mathrm{FAR}=\mathrm{GEI})$}

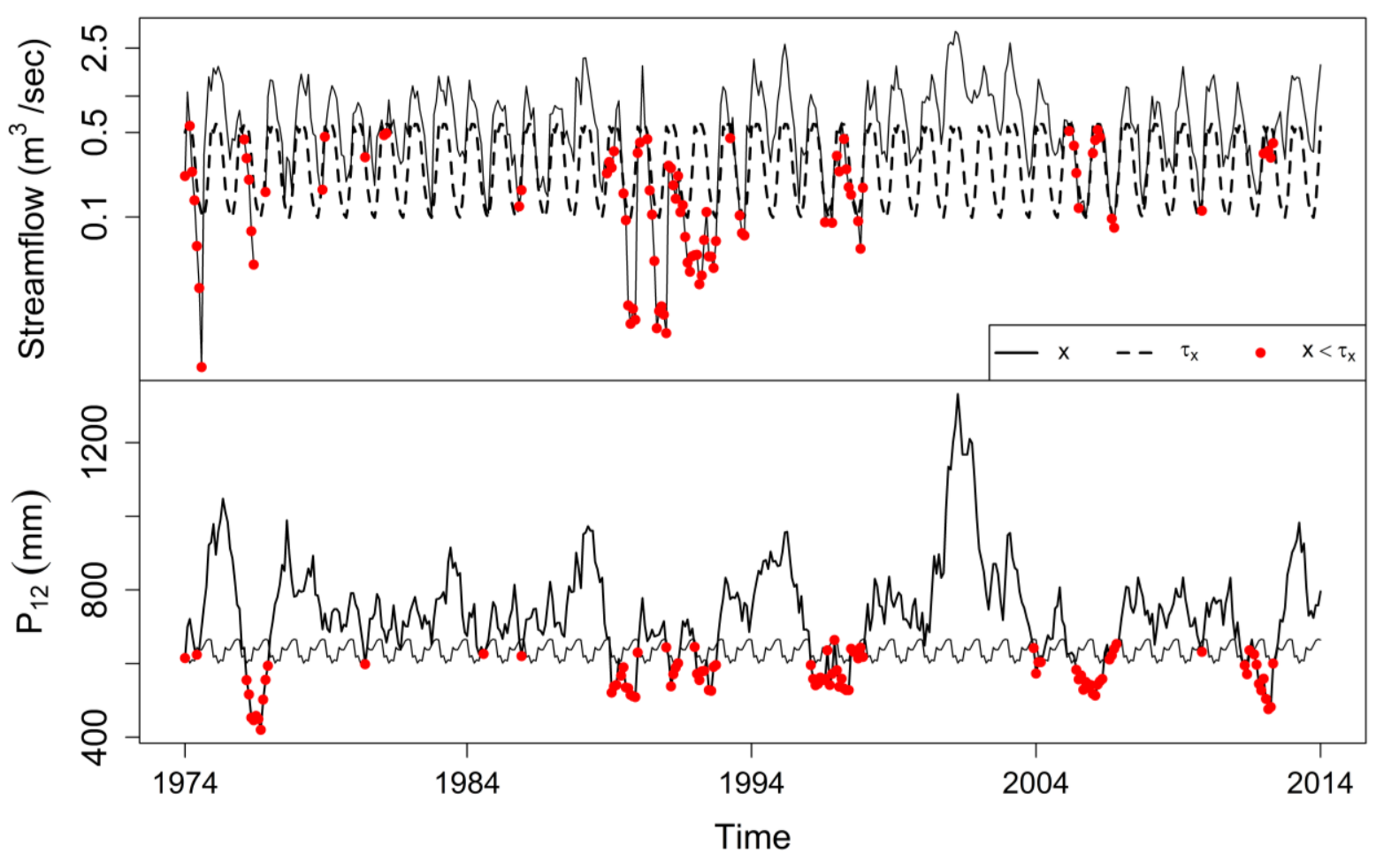

Figure 59. Monthly streamflow (upper) and precipitation accumulated over a 12-month time period ( $P_{12}$, lower) for the Darent at Hawley between 1974 and 2013.

- Catchment description: Predominantly rural chalk catchment with some expanding urban centres (BFIHOST $=0.83$ ).

- Flow record/regime description: Increasing groundwater abstraction at the beginning of the record reduced baseflows. Darent augmentation scheme (part of the alleviation of low flow) now operates and has reduced abstractions from 6 boreholes within the catchment. Water is also imported from outside the catchment to recharge the river ( $F A R=G$ ).

- Time series description: Decrease in drought occurrence towards the end of record.

- Interpretation of human influences: Decrease in streamflow drought months towards the end of record is likely to be related to the low flow alleviation measure taken within the catchment (reduction in abstraction, import of water to recharge the river). 